2021-10

Measuring optimism bias among military personnel

\title{
Cutello, CA
}

http://hdl.handle.net/10026.1/18713

10.1016/j.trf.2021.09.005

Transportation Research Part F: Traffic Psychology and Behaviour

Elsevier BV

All content in PEARL is protected by copyright law. Author manuscripts are made available in accordance with publisher policies. Please cite only the published version using the details provided on the item record or document. In the absence of an open licence (e.g. Creative Commons), permissions for further reuse of content should be sought from the publisher or author. 


\title{
Transportation Research Part F: Psychology and Behaviour
}

\section{Measuring optimism bias among military personnel}

\author{
Clara Alida Cutello ${ }^{\mathrm{a}, *}$, Clare Walsh ${ }^{\mathrm{b}}$, François Remy Foerster ${ }^{\mathrm{c}}$, Yaniv Hanoch ${ }^{\mathrm{d}}$, \\ Elizabeth Hellier ${ }^{\mathrm{b}}$
}

\footnotetext{
${ }^{\text {a }}$ Marketing Department, University of Antwerpen, Flanders, Belgium

${ }^{\mathrm{b}}$ School of Psychology, University of Plymouth, Plymouth, Devon, UK

${ }^{\mathrm{c}}$ INSERM U1114, University of Strasbourg, Strasbourg, France

${ }^{\mathrm{d}}$ Business School, University of Southampton, Southampton, UK
}

\section{A R T I C L E I N F O}

\section{Keyword:}

Driver-education interventions

Military personnel

Risky-driving behaviors

Road safety evaluation

\begin{abstract}
A B S T R A C T
High numbers of young military personnel die due to road traffic collisions (RTCs). Yet, there is a paucity of research related to the contributing factors (i.e., optimism bias and willingness to take risks) associated with RTCs and the examination of road safety education program tailored at reducing young military fatalities. In order to address this gap in the literature, we examined one specific road safety educational intervention tailored for the UK military personnel and investigated their attitudes towards the program, optimism bias and willingness to take risks. Measures evaluating their optimism bias, willingness to take risks and attitudes towards the program were asked after the participants attended the road safety interventions. The results revealed that young military personnel, aged 18-25, had higher optimism bias and willingness to take risks compared to older military personnel, and that this effect diminishes with age. The results provide importance evidence related to military personnel's attitudes to risk-taking.
\end{abstract}

\section{Introduction}

Deaths from road traffic collisions (RTCs) have been a growing safety concern for the Armed Forces around the world (DASA, 2007). Data from the US show that RTCs account for $20-40 \%$ of all young military fatalities and constitute the primary cause of unintentional injury hospitalizations within the US Armed Forces (Leland \& Oboroceanu, 2010). Quite similarly, data from the UK Armed Forces research has revealed that RTCs are the leading cause of death in peacetime (Powell, Fingerhut, Branche, \& Perrotta, 2000), and the loss of lives and injuries contribute to readiness and training costs (Thandi et al., 2015). Although RTCs among military personnel are significant financial, health and safety concern, there is a paucity of research on the contributing factors associated with RTCs. To address this gap, we examined one specific road safety educational intervention tailored for the UK military personnel and investigated their attitudes towards the program, their optimism bias and willingness to take driving risks.

\subsection{Risk-factors}

Previous research with military personal has reported that the chief risk factor for risky driving among this population is alcohol abuse. Indeed, ample evidence links excessive alcohol use and reckless driving in the Armed Forces (Fear et al., 2007; Williams, Bell, \&

\footnotetext{
* Corresponding author.

E-mail address: clara.cutello@uantwerpen.be (C.A. Cutello).
} 
Amoroso, 2002). Studies reveal that US military personal consume more alcohol compared to their civilian counterparts and they are more likely to experience alcohol related illnesses and hospitalizations (Bray, Marsden, \& Peterson, 1991) as well as RTCs (Bell, Amoroso, Yore, Smith, \& Jones, 2000; Williams et al., 2002). Other investigations have focused on the relationship between military personnel and the propensity to engage in risky behaviors (see Breivik, Sand, \& Sookermany, 2019; Fijałkowska, 2010; Garyn-Tal \& Shahrabani, 2015). The findings from this line of work has showed that military personnel are more inclined to yell, shout, drive recklessly, and consume alcohol and illegal drugs compared to the civilian population (Breivik et al., 2019; Fijałkowska, 2010; GarynTal \& Shahrabani, 2015). Research by Adler, Britt, Castro, McGurk, and Bliese (2011) also shows that undergoing military training may increase risk-taking behaviors. Adler and colleagues (2011) found that, after military training, army personnel were three times more likely to report getting into a fight, and drinking excessively compared to their behavior prior to undergoing the military training (see also Kelley et al., 2012). Another line of research has identified deployment as a risk factor for risky driving (Fear et al., 2008; Hoggatt et al., 2015).

Despite the findings mentioned above, there is a paucity of research documenting the predicting factors of risky driving behaviors amongst military personnel. In comparison, there is a large body of research focusing on young adults' risky driving behavior. As the two populations-young adults and military personnel-might share several characteristics (e.g., age) ${ }^{1}$, drawing on research with young adults could prove useful. Indeed, young adult are especially at high risk of being involved in a car collision and dying in a vehicle crash (Fear et al., 2008; Sheriff et al., 2015). Data suggests that young adults are twice as likely to engage in risk-taking behaviors, such as drinking, reckless driving, high-level speeding, or consuming illegal substances, compared to older adults (Hatfield, Fernandes, \& Job, 2014). Moreover, insufficient skills and a lack of driving experience have frequently been regarded as the main causes of collisions in this age group (Fisher et al., 2002; Underwood, 2007). Gender has also been found to predict unsafe driving behaviors (Harré, 2000; Turner \& McClure, 2003), with young males being more willing to take risks than females (Bina, Graziano, \& Bonino, 2006; Fergusson, Swain-Campbell, \& Horwood, 2003; Harré, Field, \& Kirkwood, 1996; McEvoy, Stevenson, \& Woodward, 2006; Oltedal \& Rundmo, 2006; Vassallo et al., 2007).

\subsection{Optimism bias}

In addition to the work on risk-taking and risky driving, researchers have also found a clear and consistent association between optimism bias and risky driving behaviors. Optimism bias refers to people's belief that they are more capable, competent, talented and less prone to errors than others on several personal traits and skills (Brown, 1986), one of which is driving (Pronin, Gilovich, \& Ross, 2004). Previous studies have found that compared to more experienced adults, young adults tend to focus more on the perceived benefits than the perceived costs of engaging in risky behaviors (e.g., Parsons, Siegel, \& Cousins, 1997; Reyna \& Farley, 2006) and have a greater tendency to assume that they will experience more favorable outcomes and fewer negative outcomes than their peers. Moreover, optimism bias has been associated with overconfidence (Mynttinen et al., 2009), feelings of invulnerability and illusion of control (Millstein \& Halpern-Felsher, 2002; Weinstein, 1980). Most notability, optimism bias has been associated with risky driving behaviors (Weinstein \& Lyon, 1999). The belief that one is less likely to be involved in an accident is often translated into a reduced probability of engaging in self-protective behaviors (Gosselin, Gagnon, Stinchcombe, \& Joanisse, 2010; McKenna, 1993; Mynttinen et al., 2009; Pedruzzi \& Swinbourne, 2009) or paying attention to road safety campaigns. Furthermore, these campaigns are assumed to be directed at other drivers who are less skillful, competent, or safe (Horswill, Waylen, \& Tofield, 2004; Pedruzzi, Swinbourne, \& Quirk, 2016). Thus, young drivers' overestimation of their own abilities combined with limited driving experience are considered to be critical factors in road safety (Mairean, Havarneanu, Popusoi, \& Havarneanu, 2017; Taubman-Ben, Mikulincer, \& Iram, 2004).

What about optimism bias among military personnel? To the best of our knowledge, little is known on military personnel's' optimism bias tendencies (Montes \& Weatherly, 2014). The limited data that does exists is based on studies with military pilots and showed that they were more danger-prone and had higher levels of optimism bias compared to commercial pilots (Sicard, Taillemite, Jouve, \& Blin, 2003). Would other types of military personal (non-pilots) also exhibit heightened levels of optimism bias? This idea is not without foundation, as increased feelings of "invincibility" and "invulnerability" have been commonly reported among soldiers returning from military training (Killgore et al., 2008). It is possible, therefore, that soldiers who are exposed to risky situations, experiences and training will show elevated risk of engaging in a range of domains, such as driving. Whether military personal exhibit optimism bias and whether it can help explain risky driving behavior among this population remains, however, an open empirical question. Furthermore, we know very little about any tailored programs designed to reduce risky driving behavior among military personal. Hence, in this paper, we examined military personal change in attitudes after attending a tailored road safety educational program aimed at reducing risky driving behaviors, as well as their optimism bias and willingness to take risks.

\subsection{Educational road safety interventions}

Educational road safety interventions (RSIs) are designed to change young drivers' risky behaviors and to promote road safety. To achieve these aims, RSIs are designed to raise awareness and improve insight into the risk factors that contribute to road traffic collisions, through theoretical or classroom-based lessons, and to strengthen skills of anticipatory risk in order to avoid potentially dangerous in-car situation (Bates et al., 2019; Brijs, Cuenen, Brijs, Ruiter, \& Wets, 2014). However, despite having high face validity,

\footnotetext{
${ }^{1}$ The average age of those who join the UK armed forces is 20 years and 8 months. See https://assets.publishing.service.gov.uk/government/ uploads/system/uploads/attachment_data/file/349079/PUBLIC_1409307582_attachment.pdf
} 
there is mixed evidence regarding their effectiveness (Philips, Ullberg, \& Vaa, 2010). Some studies suggest that RSIs can have shortterm benefits, by making young drivers more aware of safe driving (King, Vidourek, Love, Wegley, \& Alles-White, 2008; Nelson, Leibenluft, McClure, \& Pine, 2005) and by reducing their likelihood of being involved in a collision (Lonero \& Mayhew, 2010; Philips et al., 2010). Other research, however, has found that RSIs have limited or no impact in changing young drivers' risky behaviors (Farmer \& Wells, 2015; Glendon, McNally, Jarvis, Chalmers, \& Salisbury, 2014). For example, an evaluation of one RSIs by Cutello, Hellier, Stander, and Hanoch (2020) has reported that young male drivers exhibited riskier attitudes following the educational intervention compared to young female drivers. In addition, Glendon et al. (2014) suggested that educational RSIs may only serve to enhance young drivers' overestimation of their own driving ability (see also Brijs et al., 2014).

To our knowledge, there is a scarcity of research related to RSIs that is tailored specifically for military personnel. The present study was designed to evaluate some of the above questions. Based on the reviewed literature it was hypothesized that: a) Young military personnel should report higher levels of optimism bias compared to older military personnel; b) The participants who scored higher levels of optimism bias would also report more willingness to take risks and would rate the educational road safety intervention worst.

\subsection{The present study}

The current study reports a 1-day educational driver intervention targeting the military personnel, specifically focusing on measuring their optimism bias and their perception of the event. The study sought to investigate the role of optimism bias in military personnel using valid and reliable self-report measures.

\subsection{Educational program - Survive the drive}

Survive the Drive is a traditional fear appeal and interactive driver-education intervention. It aims to personalize the consequences of risky driving in order to reduce risky driving behavior in the Armed Forces. The intervention is structured in the following manner: after a spoken introduction by a male firefighter, a film is presented showing a group of military personnel, a woman and two men, in the moments leading up to and including a collision. As the emergency services begin to arrive the film is paused, and a member of each agency (i.e. firefighters, police, family liaisons and paramedics) comes on stage to recount a personal experience of a collision they have attended. Family members who have lost loved ones in road traffic collisions provide accounts of their loss, and a driver responsible for a collision recalls the consequences of their actions. Each speaker highlights a particular risk factor involved in the incident, and, where possible, the collisions of which they speak are local to the area of delivery and involve places or road names the military personnel will be familiar with, in order to further personalize the experience.

\section{Method}

\subsection{Participants}

A total of 118 British military personnel $(\mathrm{M}=98, \mathrm{~F}=20)$ took part in the study. They were all navy military personnel. Their length of service ranged from 1 to 48 years (Myears $=10.91$; SDyears $=9.74)$. The age of the military personnel ranged from 18 to $60+(52 \%=$ $18-25 ; 5 \%=26-34 ; 20 \%=35-44 ; 18 \%=45-54 ; 3 \%=55-60$ and $2 \%=60+$ ). The criteria to participate in the study was a valid driver's license and being enrolled in the military.

\subsection{Procedure}

Prior to its commencement, the study was approved by the authors' University Human Research Ethics Committee (ref. 18/ 19-1012) and the required ethical guidelines were adhered to throughout. Furthermore, the researchers sent emails of permission directly to the commanders of the military base. The emails outlined the nature and purpose of the study. The driving preventive program - Survive the Drive-was conducted in one military based in the south west of the UK. The program was delivered (as it usually does) by the Devon \& Somerset Fire and Rescue Service and prior to the road safety event it was contacted, informed of the research and invited to participate. After attending the driver-education intervention, participants were asked to complete the optimism bias questionnaire (Gosselin et al., 2010; McKenna \& Myers, 1997), the willingness to take risk questionnaire (Dohmen et al., 2011) and the perception of the driving-education intervention.

\subsection{Measures}

Optimism Bias Questionnaire (OB) Participants were asked to complete questions on Comparative Optimism (CO; Gosselin et al., 2010), by reading nine driving related events (i.e. yielding the right-of-way, changing lanes, crossing an intersection, merging onto the highway, driving on winding roads, driving at night, reacting quickly to unexpected events, driving when tired, and driving in poor weather conditions) and were asked to estimate their individual probability of getting into an accident compared to an average driver of their same sex and age on a 5-point Likert scale ( $1=$ much higher than average; $5=$ much lower than average).

Furthermore, participants were asked to complete the Driving Skill Questionnaire (DSQ; McKenna \& Myers, 1997), a 17-item questionnaire concerning participants' perceptions of their driving skills. They were asked to rate how good they are on a variety of driving skills, compared to the average driver of their same sex and age on a 5 -point Likert scale $(1=$ much higher than average; $5=$ 
much lower than average) $(\alpha=0.92)$.

Willingness to take risks (Dohmen et al., 2011) A one-item question that directly asked individuals to make a global assessment of their willingness to take risks: "How willing are you to take risks, in general?" Respondents rated their willingness on a scale from 1 to 5 ( 1 = Very willing to take risks; $5=$ Not at all willing to take risks).

Attitudes to Change Participants were presented with 6 driving behaviours and were asked whether their attitude to engaging in the behavior had changed following their training. Specifically, they were asked "The Survive the Drive presentation has changed my attitude to (1) driving whilst tired, (2) using the mobile phone when driving, (3) distractions within the vehicle, (4) driving under the influence of alcohol, (5) wearing a seatbelt and (6) driving at inappropriate speed. Participants were asked to tick all that applied.

\section{Results}

\subsection{Statistical analysis}

The internal consistency of the $\mathrm{OB}$ questionnaire and the attitudes to change questionnaire were determined by calculating the Cronbach's $\alpha$ scores for the items of each domain. To improve clarity, we transformed the individual scores into a percentage of maximum score values for OB sub-scales (i.e., the comparative optimisms and driving skills) and attitudes to change questionnaires. This was achieved by subtracting the minimum score possible of the given questionnaire, multiplying this value by 100 then dividing it by the maximum score possible. Such transformations allowed to compare the scores from the comparative optimisms and driving skills questionnaires. A Shapiro-Wilk test was performed to test the normality of data distribution. The test showed a significant departure from normality ( $\mathrm{W}=0.9, p<0.5$ ). Hence, non-parametric Mann-Whitney, Kruskal-Wallis and Scheirer-Ray-Hare tests were performed on the scores of the questionnaires, taking into account age, military rank, road traffic collision and deployment. Additionally, we performed Spearman Rank correlations as well as Ordinal logistical regressions. These analyses were performed in R version 2.15.3.

\subsection{Optimism bias}

Our first goal was to determine whether military personnel reported optimistic bias and, specifically, whether they were differences between young military personnel and older military personnel. A Mann-Whitney $U$ test with a central value of $50 \%$ (i.e., neither optimistic nor pessimistic) showed that our sample reported significant levels of optimism bias when comparing themselves to an average driver $(\mathrm{U}=7021, \mathrm{p}<.0001$, Mean OB score $=61.3 \%)$.

The young military personnel, aged 18-25, represented the majority of the low-ranking officers (93.5\%), and were underrepresented in higher ranks (7.1\%). A Kruskal-Wallis test showed a main effect of age on optimism bias scores $\mathrm{H}(5)=75.62, \mathrm{p}<$ .0001. A Dunn's post-hoc comparison showed that higher levels of optimism bias were reported by young military officers (18-25 years old; $\mathrm{M}=76.9 \%$; $\mathrm{SD}=9.18 \%, \mathrm{p}<.001)$ compared to the rest of military officers $(26-34, \mathrm{M}=48.6 \%, \mathrm{SD}=6.39 \% ; 35-44, \mathrm{M}=$ $44 \%, \mathrm{SD}=16.5 \% ; 45-56, \mathrm{M}=43.52 \%, \mathrm{SD}=13.7 \% ; 55-60, \mathrm{M}=39.9 \%, \mathrm{SD}=16.8 \%>25$ years old; $\mathrm{M}=44.1 \%$; $\mathrm{SD}=15.2 \%$; all $\mathrm{p}>$ .02 see Fig. 1A, Fig. 1B). Corroborating this result, a further Mann-Whitney test displayed a main effect of rank on optimism bias (U =

A

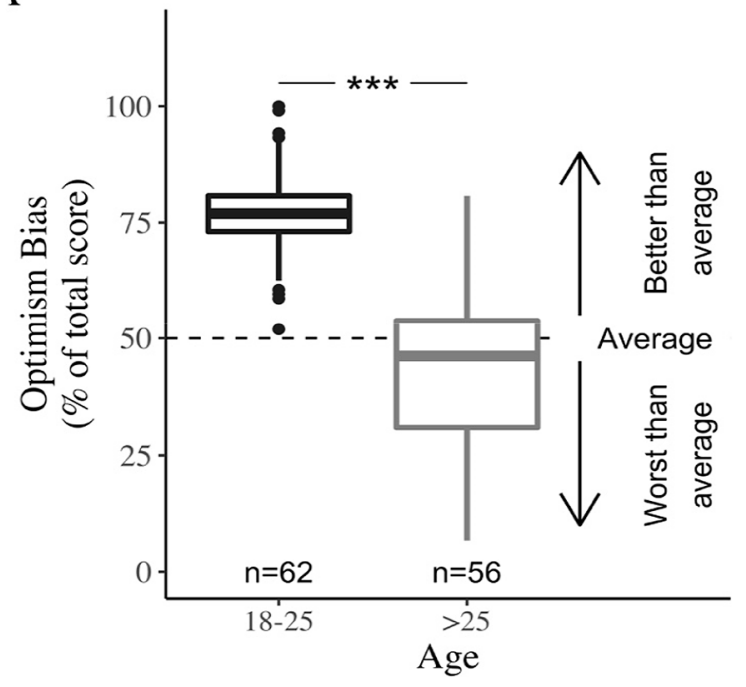

B

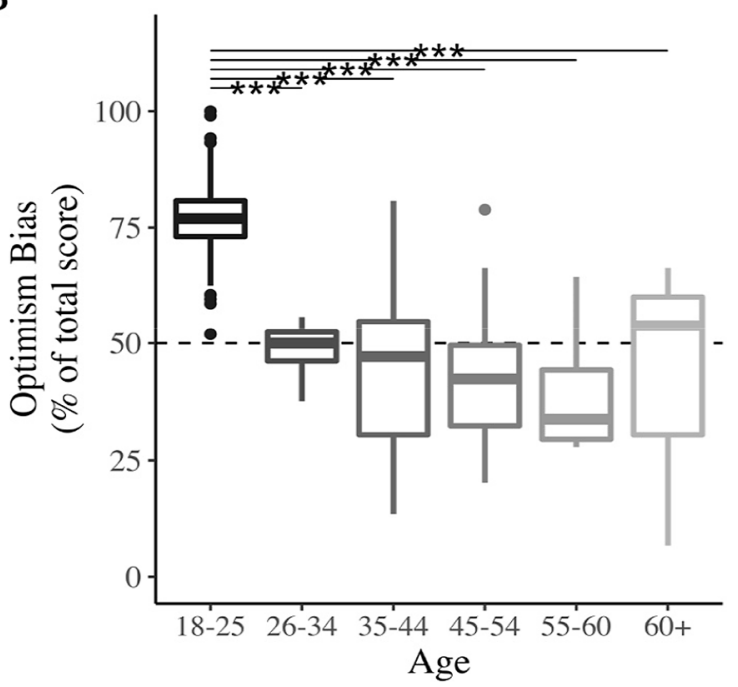

Fig. 1. A: Participants OB scores, split into two equivalent age groups (18-25; >25). B: Participants OB scores, split by all the age groups. Error bars represent $95 \%$ of confidence intervals. 
303, $\mathrm{p}<.0001)$, where low-ranking military personnel displayed more optimistic bias $(\mathrm{M}=75.4 \%$; $\mathrm{SD}=11.1 \%)$ than high-ranking military personnel $(\mathrm{M}=45.8 \%$; $\mathrm{SD}=17.3 \%)$.

We analyzed the two OB scales separately to see if the military personnel were more optimistic in one questionnaire rather than the other. Once again, a Kruskal-Wallis test revealed a significant effect of age group in both the in both the comparative optimisms (H(5) $=68.26, p<.0001)$, as well as the driving skills questionnaire $(\mathrm{H}(5)=68.19, p<.0001)$. Dunn's post-hoc comparison illustrated that the military personnel aged $18-25$ reported more optimistic bias across questionnaires $(p<.001)$ compared to older military personnel (all $p>$.07).

\subsection{Willingness to take risks}

Next, because no differences were found between participants older than 18-25, we cluster the participants into two groups (18-25 vs $>25$ ). A Mann-Winn test was performed to evaluate the effect of age on the willingness to take risks. It revealed a main effect of age on willingness to take risks, $\mathrm{U}=607, p<.0001$, with young military personnel reporting more willingness to take risks ( $\mathrm{M}=1.52$; $\mathrm{SD}$ $=0.92 ; p<.001)$ than older military personnel $(\mathrm{M}=2.79 ; \mathrm{SD}=1.06$; See Fig. 2$)$. A Spearman correlation showed that optimism bias was correlated with the reported willingness to take risks $\left(r_{s}=-0.422, p<.0001\right)$, such as the military personal that reported higher willing to take risks had the highest scores to the optimism bias questionnaire. However, an ordinal logistic regression showed no significant effect of willingness to take risks on participants' optimism bias after controlling for the participants' age ( $\mathrm{p}=0.2)$. The results suggest that younger adults are both more likely to show an optimism bias and be willing to take risks but these two factors are not related to one another once we control for age.

\subsection{Attitudes to change}

Regarding the attitude to change, regression analyses were computed to explore the interrelations between participants' attitudes to change and age, OB scores, willingness to take risks scores. The regression analysis indicated that optimism bias, willingness to take risks and age were not associated with attitudes to change $\left(\mathrm{r}_{\mathrm{s}}=-0.40\right.$, all $\left.p=0.7\right)$. Furthermore, logistical regression analysis on the attitudes to change subscales, did not reveal any differences (all $p>.09$ ).

\subsection{Road traffic collisions and deployment}

We then performed analyses to evaluate the link between road traffic collisions and deployment on participants' optimism bias, willingness to take risks and attitude to change. We asked participants to indicate whether they had been in a road traffic collision either while on duty (1), while off duty (2) or not at all (3). As there were very few accidents while on duty, we then merged the categories for on and off duty to identify if they had been in a collision in general or not.

We ran three Scheirer-Ray-Hare tests to look at the effect of age and prior road traffic collision on participants' optimism bias, willingness to take risks and attitudes to change. In all cases, the findings did not reveal any significant effect of road traffic collisions on participants' OB scores ( $\mathrm{p}=0.4)$, nor on willingness to take risks $(p=0.2)$, or attitudes to change $(p=0.3)$. As before, age had a major effect, $\mathrm{H}(1,114)=72.70, p<.0001$. However, no interaction effects were found.

Finally, we conducted a Scheirer-Ray-Hare test to evaluate the impact of deployment and age on optimism bias. We asked

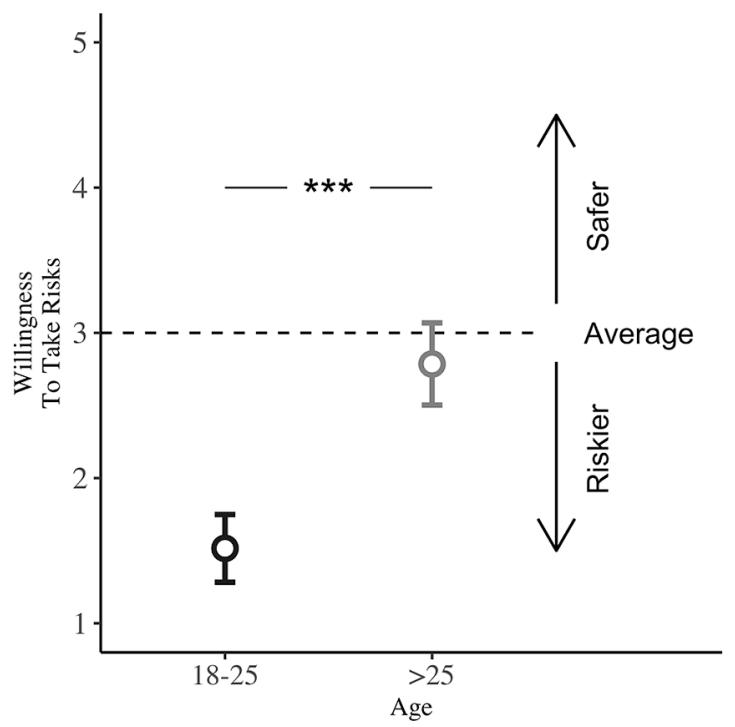

Fig. 2. Participant's willingness to take risks scores, split into two age groups (18-25; >25). Error bars represent $95 \%$ of confidence intervals. 
participants to indicate whether they had returned from active service in the last year (1), from training in the last year (2) or none of the above (3). As there were very few participants that had returned from active service, we merged the answers into two categories to identify if the participants had been deployed or not. The findings revealed that deployment did not influence the participants' optimism bias, although the results were marginal $(p=0.6)$, and as before, age did have an effect, $\mathrm{H}(1,114)=37.60, p<.001$. We also performed a Scheirer-Ray-Hare test to evaluate the impact of the deployment and age on the participants' willingness to take risks. There was only a an interaction effect between age and deployment $\mathrm{H}(1,114)=8.19, \mathrm{p}<.05$. Dunn post-hoc comparison indicated that young military personnel who had been deployed the year before reported less willingness to take risks $(M=2.14$; $S D=1.09)$ than young military personnel who hadn't been deployed $(\mathrm{M}=1.33$; $\mathrm{SD}=0.78, p=.031$ ), whereas no significant difference was reported in the older military $(\mathrm{p}=.43)$. A last Scheirer-Ray-Hare test was done to evaluate the effect of deployment and age on military's attitude towards change, which did not reveal any main effect or interaction between the variables.

\section{Discussion}

According to DASA (2007), military personnel's deaths from road traffic collisions have been a growing safety concern worldwide. In the US, RTCs are the leading cause of fatalities and a leading cause of nonfatal injury among U.S. military personnel (Jones, CanhamChervak, Canada, Mitchener, \& Moore, 2010; Powell et al., 2000). Despite the high numbers of young military fatalities due to RTCs, research related to the contributing factors (i.e. optimism bias and willingness to take risks) associated with RTCs and the examination of road safety education program tailored at reducing young military fatalities are few and far between. In order to address this gap in the literature, we examined one specific road safety educational intervention tailored for the UK military personnel and assessed their attitudes towards the program, their optimism bias and willingness to take risks.

Firstly, we hypothesized that young military personnel would report higher levels of optimism bias compared to older military personnel. The results corroborate our hypothesis, revealing that optimism bias was predicted by age. Specifically, young military personnel, aged 18-25, considered their own driving skills as better than their average peer and underestimated the probability of negative events (e.g., collisions) occurring. Consequently, our findings are consistent with previous work on young drivers and optimism bias. In particular, they mirror those of previous work which found that young drivers aged 18-25 report higher tendency to perceive themselves as better than their same-age peers and underestimate their personal risk compared to others (Fernandes, Job, \& Hatfield, 2007; Gosselin et al., 2010; Harré \& Sibley, 2007; White, Cunningham, \& Titchener, 2011). Furthermore, when examining the results for each age cohort it appears that optimism bias diminishes with age, which is also aligned with previous findings showing that drivers' levels of optimism bias vary by age (Finn \& Bragg, 1986; Matthews \& Moran, 1986).

Secondly, we predicted that those who would report higher levels of optimism bias would also display higher willingness to take risks and would rate the educational road safety event worst. Our data revealed that willingness to take risks was predicted by age. Indeed, young military personnel were more willing to take risks compared to older military personnel. These findings are in accordance with previous work, in which young drivers were found to be more willing to take risks because of their persistent bias in their perception of risks (Chraif, Anitei, \& Alex, 2013; Măirean \& Havârneanu, 2018), as well as a general propensity towards deliberately engaging in high-risk behaviors (Ulleberg, 2001).

Furthermore, optimism bias and higher willingness to take risks have been linked with inexperience (Bingham et al., 2016; Williams, 2006). Specifically, it has been argued that young people's lack of experience fuels their overestimation of their skills and underestimation of the dangers, believing that they they are at lower risk to become involved in an accident compared to older adults and peers (Constantinou, Panayiotou, Konstantinou, Loutsiou-Ladd, \& Kapardis, 2011). At the same time, while underestimating the risks, young inexperienced drivers have been found to act more recklessly and aggressively compared to more experienced drivers (Chen, Baker, Braver, \& Li, 2000; Heck \& Carlos, 2006). These findings were partially sustained by our post-hoc results, in which experience military personnel who had return from military deployment were less optimistic about their driving skills compared to those who had not. Similarly, young military personnel who had been deployed the year before reported less willingness to take risks than young military personnel who hadn't been deployed.

However, our results did not support our hypothesis that those who rated themselves as more skilled and less-accident prone than their peers would also be less inclined to change their attitudes after attending the road safety intervention. Thus, our results cannot provide evidence that military personnel who report higher levels of optimism bias would be less inclined to change their behaviours through a road safety educational intervention.

Taken together our data not only provides, to our knowledge, the first empirical evidence of military's personal tendency to exhibit optimism bias, but also illustrates how young people perceive their own driving skills as better than their average peer and underestimated the probability of negative events occurring, which can be detrimental when trying to persuade them to change their risky behaviors.

This study has several limitations. First, this was not a longitudinal study aimed to evaluate whether the RSI could have been effective in reducing military personnel's optimism bias and willingness to take risks. Future research would need to evaluate whether similar interventions have a long-lasting effect among military personnel. At this point, we are unable to indicate if the RSI would have an impact on the military's optimism bias and willingness to take risks. Second, our sample is not necessarily representative of the entire military personnel, so further studies are necessary to assess the military personnel more in depth. Needless to say, further research is urgently needed to examine these important factors.

In summary, military personnel's RTCs are the leading cause of death in peacetime and the research related to the contributing factors (i.e. optimism bias and willingness to take risks) associated with RTCs are few and far between. This research not only provides the first empirical evidence of military's optimism bias, but also illustrates how young people perceive their own driving skills as better 
than their average peer, underestimated the probability of negative events occurring, and are more willing to take risks compared to older military personnel. It is important to acknowledge these factors when creating tailored RSIs, because they can be detrimental when trying to persuade young people to change their risky behaviors. Taking them into account can help decrease young drivers' overrepresented in road traffic collisions. Nevertheless, while we focused solely on driver safety, it is important that future studies extend our results to other domains.

The authors declared that they had no conflicts of interest with respect to their authorship or the publication of this article.

\section{CRediT authorship contribution statement}

Samantha N. Emerson: Data curation, Formal analysis, Visualization, Writing - original draft. Valery D. Limia: Writing - original draft, Writing - review \& editing. Şeyda Özçalışkan: Conceptualization, Data curation, Funding acquisition, Investigation, Methodology, Project administration, Resources, Supervision, Validation, Writing - review \& editing.

\section{Declaration of Competing Interest}

The authors declare that they have no known competing financial interests or personal relationships that could have appeared to influence the work reported in this paper.

\section{References}

Adler, A. B., Britt, T. W., Castro, C. A., McGurk, D., \& Bliese, P. D. (2011). Effect of transition home from combat on risk-taking and health-related behaviors. Journal of Traumatic Stress, 24(4), 381-389.

Bates, L., Hawkins, A., Rodwell, D., Anderson, L., Watson, B., Filtness, A., \& Larue, G. S. (2019). The effect of psychosocial factors on perceptions of driver education using the goals for diver education framework. Transportation Research Part F: Traffic Psychology and Behavior, 66, $151-161$.

Bell, N. S., Amoroso, P. J., Yore, M. M., Smith, G. S., \& Jones, B. H. (2000). Self-reported risk-taking behaviors and hospitalization for motor vehicle injury among active duty army personnel. American Journal of Preventive Medicine, 18, 85-95.

Bina, M., Graziano, F., \& Bonino, S. (2006). Risky driving and lifestyles in adolescence. Accident Analysis and Prevention, 38(3), 472-481. https://doi.org/10.1016/j. aap.2005.11.003

Bingham, C. R., Simons-Morton, B. G., Pradhan, A. K., Li, K., Almani, F., Falk, E. B., Shope, J. T., et al. (2016). Peer passenger norms and pressure: Experimental effects on simulated driving among teenage males. Transportation Research Part F: Traffic Psychology and Behavior, 41, 124-137. https://doi.org/10.1016/j. trf.2016.06.007

Bray, R. M., Marsden, M. E., \& Peterson, M. R. (1991). Standardized comparisons of the use of alcohol, drugs, and cigarettes among military personnel and civilians. American journal of public health, 81(7), 865-869. https://doi.org/10.2105/ajph.81.7.865

Breivik, G., Sand, T., \& Sookermany, A. (2019). Risk-Taking and Sensation Seeking in Military Contexts: A Literature Review. SAGE Open., 9. https://doi.org/10.1177/ 2158244018824498

Brijs, K., Cuenen, A., Brijs, T., Ruiter, R. A. C., \& Wets, G. (2014). Evaluating the effectiveness of post-license education program for young novice drivers in Belgium. Accident Analysis and Prevention, 66, 62-71.

Brown, J. D. (1986). Evaluations of self and others: Self-enhancement biases in social judgments. Social Cognition, 4(4), 353-376. https://doi.org/10.1521/ soco.1986.4.4.353

Chen, L. H., Baker, S. P., Braver, E. R., \& Li, G. (2000). Carrying passengers as a risk factor for crashes fatal to 16- and 17-year-old drivers. JAMA, 283, 1578-1582.

Chraif, M., Anitei, M., \& Alex, S. (2013). The Effects of Exposure to the Publicity Campaign "Stop the Accidents" on the Willingness to Take Risks in Traffic Situations. Procedia - Social and Behavioral Sciences, 78, 562-566. https://doi.org/10.1016/j.sbspro.2013.04.351

Constantinou, E., Panayiotou, G., Konstantinou, N., Loutsiou-Ladd, A., \& Kapardis, A. (2011). Risky and aggressive driving in young adults: Personality matters. Accident Analysis and Prevention, 43(4), 1323-1331.

Cutello, C. A., Hellier, E., Stander, J., \& Hanoch, Y. (2020). Evaluating the effectiveness of a young driver-education intervention: Learn2Live. Transportation Research Part F: Traffic Psychology and Behavior, 69, 375-384. https://doi.org/10.1016/j.trf.2020.02.009

DASA Statistical Notice. (2007). Deaths in the UK Regular Armed Forces 2006. London: Defence Analytical Services Agency. www.dasa.mod.uk/natstats/deaths/pdfs/ deaths01mar07.pdf.

Dohmen, T., Falk, A., Huffman, D., Sunde, W., Schupp, J., \& Wagner, G. G. (2011). Individual Risk Attitudes: Measures, Determinants, and Behavioral Consequences. Journal of the European Economic Association, 9(3), 522-550. https://doi.org/10.1111/j.1542-4774.2011.01015.x

Farmer, C. M., \& Wells, J. K. (2015). Crash and Citation Records of Young Drivers with Skid Avoidance Training. VA: Retrieved from Alrington.

Fear, N. T., Iversen, A. C., Chatterjee, A., Jones, M., Greenberg, N., Hull, L., Rona, R. J., Hotopf, M., \& Wessely, S. (2008). Risky driving among regular armed forces personnel from the United Kingdom. American Journal of Preventive Medicine, 35(3), 230-236. https://doi.org/10.1016/j.amepre.2008.05.027

Fear, N. T., Iversen, A. C., Meltzer, H., Workman, L., Hull, L., Greenberg, N., Barker, C., Browne, T., Earnshaw, M., Horn, O., Jones, M., Rona, R., Hotopf, M., \& Wessely, S. (2007). Patterns of drinking in the UK Armed Forces. Addiction (Abingdon, England)., 102, 1749-1759. https://doi.org/10.1111/j.13600443.2007.01978.x

Fergusson, David, Swain-Campbell, Nicola, \& Horwood, John (2003). Risky driving behaviour in young people: prevalence, personal characteristics and traffic accidents. Australian and New Zealand Journal of Public Health, 27(3), 337-342. https://doi.org/10.1111/j.1467-842x.2003.tb00404.x

Fernandes, R., Job, R. F. S., \& Hatfield, J. (2007). A challenge to the assumed generalizability of prediction and countermeasure for risky driving: Different factors predict different risky driving behaviors. Journal of Safety Research, 38(1), 59-70. https://doi.org/10.1016/j.jsr.2006.09.003

Finn, P., \& Bragg, B. W. (1986). Perception of the risk of an accident by young and older drivers. Accident Analysis and Prevention, 18(4), 289-298. https://doi.org/ 10.1016/0001-4575(86)90043-6

Fijałkowska, S. (2010). Implications of the level of dogmatism and selected psychosocial conditions for a propensity for risky behavior among the soldiers of the Polish army land forces. Journal for Perspectives of Economic Political and Social Integration, 16, 155-172.

Fisher, D. L., Laurie, N. E., Glaser, R., Connerney, K., Pollatsek, A., Duffy, S. A., \& Brock, J. (2002). Use of a Fixed-Base Driving Simulator to Evaluate the Effects of Experience and PC-Based Risk Awareness Training on Drivers' Decisions. Human Factors: The Journal of the Human Factors and Ergonomics Society, 44(2), 287-302. https://doi.org/10.1518/0018720024497853

Garyn-Tal, S., \& Shahrabani, S. (2015). Type of army service and decision to engage in risky behavior among young people in Israel. Judgment and decision making., 10, $342-354$.

Glendon, A. I., McNally, B., Jarvis, A., Chalmers, S. L., \& Salisbury, R. L. (2014). Evaluating a novice driver and pre-driver road safety intervention. Accident Analysis and Prevention, 64, 100-110.

Gosselin, D., Gagnon, S., Stinchcombe, A., \& Joanisse, Mélanie (2010). Comparative optimism among drivers: An intergenerational portrait. Accident Analysis and Prevention, 42(2), 734-740. 
Harré, N. (2000). Risk Evaluation, Driving, and Adolescents: A Typology. Developmental Review, 20(2), 206-226. https://doi.org/10.1006/drev.1999.0498

Harré, N., \& Sibley, C. G. (2007). Explicit and implicit self-enhancement biases in drivers and their relationship to driving violations and crash-risk optimism. Collision Analysis and Prevention, 39(6), 1155-1161. https://doi.org/10.1016/j.aap.2007.03.001

Harré, N., Field, J., \& Kirkwood, B. (1996). Gender differences and areas of common concern in the driving behaviors and attitudes of adolescents. Journal of Safety Research, 27(3), 163-173. https://doi.org/10.1016/0022-4375(96)00013-8

Hatfield, J., Fernandes, R., \& Job, R. F. S. (2014). Thrill and Adventure Seeking as a modifier of the relationship of perceived risk with risky driving among young drivers. Accident Analysis and Prevention, 62, 223-229.

Heck, K., \& Carlos, R. M. (2006). Adolescents and Driving Safety. Center for Youth Development, 11(8), 1-9. https://doi.org/10.1097/00006205-198608000-00013

Hoggatt, K. J., Prescott, M. R., Goldmann, E., Tamburrino, M., Calabrese, J. R., Liberzon, I., \& Galea, S. (2015). The prevalence and correlates of risky driving behavior among National Guard soldiers. Traffic Injury and Prevention, 16(1), 17-23. https://doi.org/10.1080/15389588.2014.896994

Horswill, M., Waylen, A., \& Tofield, M. (2004). Drivers' Ratings of Different Components of Their Own Driving Skill: A Greater Illusion of Superiority for Skills That Relate to Accident Involvement. Journal of Applied Social Psychology., 34. https://doi.org/10.1111/j.1559-1816.2004.tb02543.x

Jones, B. H., Canham-Chervak, M., Canada, S., Mitchener, T. A., \& Moore, S. (2010). Medical surveillance of injuries in US military: Descriptive epidemiology and recommendations for improvement. American Journal of Preventive Medicine, 38(1), S42-S60. https://doi.org/10.1016/j.amepre.2009.10.014

Kelley, A. M., Athy, J. R., Cho, T. H., Erickson, B., King, M., \& Cruz, P. (2012). Risk propensity and health risk behaviors in USA army soldiers with and without psychological disturbances across the deployment cycle. US Army Research, 200.

Killgore, W. D., Cotting, D. I., Thomas, J. L., Cox, A. L., McGurk, D., Vo, A. H., Castro, C. A., \& Hoge, C. W. (2008). Post-combat invincibility: Violent combat experiences are associated with increased risk-taking propensity following deployment. Journal of Psychiatric Research, 42(13), $1112-1121$.

Leland, A., \& Oboroceanu, M. J., (2010). American war and military operations casualties: Lists and statistics. In CRS Report for Congress. Washington, DC: Congressional Research Service (US). Report No: RL32492.

King, K. A., Vidourek, R. A., Love, J., Wegley, S., \& Alles-White, M. (2008). Teaching adolescents safe driving and passenger behaviors: Effectiveness of the You Hold the Key Teen Driving Countermeasure. Journal of Safety Research, 39(1), 19-24. https://doi.org/10.1016/j.jsr.2007.10.006

Lonero, L., \& Mayhew, D., (2010). Review of the literature on driver education evaluation 2010 update. AAA Foundation for Traffic Safety Retrieved from https:// www.aaafoundation.org/sites/default/files/LSEDElitReview.pdf.

Matthews, M. L., \& Moran, A. R. (1986). Age differences in male drivers' perception of accident risk: The role of perceived driving ability. Accident Analysis and Prevention, 18(4), 299-313. https://doi.org/10.1016/0001-4575(86)90044-8

Mairean, C., Havarneanu, G., Popusoi, S., \& Havarneanu, C. (2017). Traffic locus of control scale -Romanian version: Psychometric properties and relations to the driver's personality, risk perception, and driving behavior. Transportation Research Part F: Traffic Psychology and Behavior., 45, 131-146. https://doi.org/10.1016/ j.trf.2016.12.008

Măirean, C., \& Havârneanu, C. (2018). The relationship between drivers' illusion of superiority, aggressive driving, and self-reported risky driving behaviors. Transportation Research Part F: Traffic Psychology and Behavior, 55, 167-172. https://doi.org/10.1016/j.trf.2018.02.037

McEvoy, S. P., Stevenson, M. R., \& Woodward, M. (2006). The impact of driver distraction on road safety: Results from a representative survey in two Australian states. Injury prevention: Journal of the International Society for Child and Adolescent Injury Prevention, 12(4), 242-247. https://doi.org/10.1136/ip.2006.012336

McKenna, F. P. (1993). It won't happen to me: Unrealistic optimism or illusion of control? British Journal of Psychology, 84(1), 39-50. https://doi.org/10.1111/j.20448295.1993.tb02461.x

McKenna, F. P., \& Myers, L. B. (1997). Illusory self-assessments-Can they be reduced? British Journal of Psychology, 88(1), 39-51.

Millstein, S., \& Halpern-Felsher, B. (2002). Judgments About Risk and Perceived Invulnerability in Adolescents and Young Adults. Journal of Research on Adolescence., 12, 399-422. https://doi.org/10.1111/1532-7795.00039

Montes, K. S., \& Weatherly, J. N. (2014). The Relationship Between Personality Traits and Military Enlistment: An Exploratory Study. Military Behavioral Health, 2(1), 98-104.

Mynttinen, S., Sundström, A., Koivukoski, M., Hakuli, K., Keskinen, E., \& Henriksson, W. (2009). Are novice drivers overconfident? A comparison of self-assessed and examiner-assessed driver competences in a Finnish and Swedish sample. Transportation Research Part F: Traffic Psychology and Behavior, 12(2), 120-130. https:// doi.org/10.1016/j.trf.2008.09.002

Mynttinen, S., Sundström, A., Koivukoski, M., Hakuli, K., Keskinen, E., \& Henriksson, W. (2009). Are novice drivers overconfident? A comparison of self-assessed and examiner-assessed driver competences in a Finnish and Swedish sample. Transportation Research Part F: Traffic Psychology and Behaviour, 12(2), 120-130. https:// doi.org/10.1016/j.trf.2008.09.002

Nelson, E. E., Leibenluft, E., McClure, E. B., \& Pine, D. S. (2005). The social re-orientation of adolescence: A neuroscience perspective on the process and its relation to psychopathology. Psychological Medicine, 35(2), 163-174. https://doi.org/10.1017/S0033291704003915

Oltedal, S., \& Rundmo, T. (2006). The effects of personality and gender on risky driving behavior and accident involvement. Safety Science, 44(7), 621-628. https:// doi.org/10.1016/j.ssci.2005.12.003

Parsons, J. T., Siegel, A. W., \& Cousins, J. H. (1997). Late adolescent risk-taking: Effects of perceived benefits and perceived risks on behavioral intentions and behavioral change. Journal of Adolescence, 20, 381-392. https://doi.org/10.1006/jado.1997.0094

Pedruzzi, R., \& Swinbourne, A.L., (2009) "It won't happen to me:" optimism, biases, and recall of road-risk information. In Proceedings of the Australian College of Road Safety Conference (pp. 1-12). Perth, WA, Australia: Australian College of Road Safety Conference 2009: road safety 2020: smart solutions, sustainability, vision, 5-6 November 2009.

Pedruzzi, R., Swinbourne, A., \& Quirk, F., (2016). Framing road risks: Why road crash messages don't put people in the driver's seat. In Conference: Australian Road Safety Conference, At Canberra, Volume: Agility, Innovation, Impact!

Philips, R. O., Ullberg, P., \& Vaa, T. (2010). Meta-analysis of the effect of road safety campaigns on accidents. Accident Analysis and Prevention, 43(3), 1204-1218. https://doi.org/10.1016/j.aap.2011.01.002

Powell, K. E., Fingerhut, L. A., Branche, C. M., \& Perrotta, D. M. (2000). Deaths Due to Injury in the Military. American Journal of Preventive Medicine, 18(3), 26-32.

Pronin, E., Gilovich, T., \& Ross, L. (2004). Objectivity in the eye of the beholder: Divergent perceptions of bias in self versus others. Psychological Review, 111, 781-799. https://doi.org/10.1037/0033-295X.111.3.781

Reyna, V. F., \& Farley, F. (2006). Risk and rationality in adolescent decision-making: Implications for theory, practice, and public policy. Psychological Science in the Public Interest., 7, 1-44.

Sheriff, R. J. S., Forbes, H. J., Wessely, S. C., Greenberg, N., Jones, N., Fertout, M., Harrison, K., \& Fear, N. T. (2015). Risky driving among UK regular armed forces personnel: Changes over time. BMJ Open, 5(9), e008434. https://doi.org/10.1136/bmjopen-2015-008434

Sicard, B., Taillemite, J. P., Jouve, E., \& Blin, O. (2003). Risk propensity in commercial and military pilots. Aviation, Space and Environmental Medicine, 74, 879-881.

Taubman-Ben, A. O., Mikulincer, M., \& Iram, A. (2004). A multi-factorial framework for understanding reckless driving-appraisal indicators and perceived environmental determinants. Transportation Research Part F: Traffic Psychology and Behavior., 7, 333-349. https://doi.org/10.1016/j.trf.2004.10.001

Thandi, G., Sundin, J., Dandeker, C., Jones, N., Greenberg, N., Wessely, S., \& Fear, N. T. (2015). Risk-taking behaviors among Uk military reservists. Occupational Medicine, 65, 413-416. https://doi.org/10.1093/occmed/kqv057

Turner, C., \& McClure, R. (2003). Age and gender differences in risk-taking behavior as an explanation for high incidence of motor vehicle crashes as a driver in young males. Injury Control and Safety Promotion, 10(3), 123-130. https://doi.org/10.1076/icsp.10.3.123.14560

Ulleberg, P. (2001). Personality subtypes of young drivers. Relationship to risk-taking preferences, accident involvement, and response to a traffic safety campaign. Transportation Research Part F: Traffic Psychology and Behaviour, 4(4), 279-297. https://doi.org/10.1016/S1369-8478(01)00029-8

Underwood, G. (2007). Visual attention and the transition from novice to advanced driver. Ergonomics, 50(8), 1235-1249. https://doi.org/10.1080/ 00140130701318707

Vassallo, S., Smart, D., Sanson, A., Harrison, W., Harris, A., Cockfield, S., \& McIntyre, A. (2007). Risky driving among young Australian drivers: Trends, precursors and correlates. Accident Analysis and Prevention, 39(3), 444-458. https://doi.org/10.1016/j.aap.2006.04.011 
Weinstein, N. D. (1980). Unrealistic optimism about future life events. Journal of Personality and Social Psychology, 39(5), 806-820. https://doi.org/10.1037/00223514.39.5.806

Weinstein, N. D., \& Lyon, J. E. (1999). Mindset, optimistic bias about personal risk and health-protective behavior. British Journal of Health Psychology, 4(Part 4), 289-300. https://doi.org/10.1348/135910799168641

White, M. J., Cunningham, L. C., \& Titchener, K. (2011). Young drivers' optimism bias for collision risk and driving skill: Accountability and insight experience manipulations. Collision Analysis and Prevention., 43(4), 1309-1315. https://doi.org/10.1016/j.aap.2011.01.013

Williams, J. O., Bell, N. S., \& Amoroso, P. J. (2002). Drinking and other risk taking behaviors of enlisted male soldiers in the US Army. Work, 18(2), 141-150.

Williams, A. F. (2006). Young driver risk factors: Successful and unsuccessful approaches for dealing with them and an agenda for the future. Injury Prevention, 12 (suppl_1), i4-i8. https://doi.org/10.1136/ip.2006.011783 